DOI:

УДК: $621.771 .25 / 26$

С.К. Мещанінов д.т.н., професор

О.В. Сай, аспірант

В.В. Багрій, к.т.н., доцент

Р.В. Волошин, завідувач лабораторії

Дніпровський державний технічний університет, м. Кам’янське

\title{
ДІАГНОСТИКА АВТОМАТИЗОВАНИХ СИСТЕМ ПРОКАТНИХ СТАНІВ З ВИКОРИСТАННЯМ НЕЙРОННОЇ МЕРЕЖІ
}

В роботі наведено метод оцінки стану електричних приводів, заснований на побудові нейронної мережі. На прикладі електроприводу постійного струму описаний експеримент, який показує ефективність даного підходу. Цей метод може знайти застосування для діагностики стану електроприводів прокатних станів металургійного виробництва.

Ключові слова: електропривод постійного струму; нейронна мережа; ідентифікація динамічних об'єктів; системи управління.

The paper presents a method of estimating the state of electric drives based on the construction for a neural network. The example of a DC electric drive describes an experiment that demonstrates the effectiveness of this approach. This method can be used to diagnose the condition of electric drives of rolling mills of metallurgical production.

Keywords: diagnose the condition of electric drives, DC drives, control system, automatic control of electric drives.

\section{Постановка проблеми}

В даний час застосування мікропроцесорної техніки посприяло «інтелектуалізації» промислового обладнання. Яскравий приклад тому - електричні приводи, що представляють собою системи, здатні до, самоналаштування і адаптації. Подібні системи набувають все більшого поширення в якості приводної техніки для високопродуктивних ліній. У металургійній промисловості автоматизований електричний привід застосовується в переважній більшості установок і технологічних комплексів. До половини всієї споживаної металургійними підприємствами електроенергії припадає на електроприводну техніку $[1,2]$.

Особливі вимоги в металургії пред'являються до автоматизованих електроприводів листових безперервних прокатних станів: там традиційно застосовуються електроприводи постійного струму 3 незалежним збудженням, що мають хороші експлуатаційні показники в умовах динамічних навантажень і здатні забезпечити плавне регулювання швидкостей в широких діапазонах. Як і будь-які інші технічні пристрої, електроприводи прокатних станів потребують обслуговування. При цьому якість експлуатації електроприводів і ефективне планування ремонтних і налагоджувальних робіт побічно впливають на такі показники виробництва, як: продуктивність прокатного стану, якість прокату і собівартість продукції. Оптимальна настройка системи управління дозволяє знизити споживання електричної енергії станом і уникнути браку, а своєчасне виявлення несправності на початковій стадії дозволяє уникнути дорогого ремонту і простою всього прокатного стану. Існуючі системи автоматичного керування електроприводами безперервних листових прокатних станів здатні оперативне виявляти і локалізувати виникнення аварійних ситуацій. До таких ситуацій можна віднести неполадки в перетворювальної техніці, електродвигунах або механічної частини. Однак виявлення несправності системою автоматики часто відбувається на тієї стадії, коли руйнування значні і вимагають істотних ремонтів.

Такі провісники неполадок, як коливальний характер швидкості, погіршення якості перехідних процесів, старіння підшипникових вузлів або механічних передач, не фіксуються датчиками в початковій стадії. Виявити їх в даний час можуть тільки кваліфіковані фахівці, використовуючи відповідні прилади та аналітичні експертні методи. Вони аналізують сукупність ознак в роботі обладнання за даними з різних приладів і здатні оцінити всю динаміку процесів. 
Гарний спеціаліст з аналізу осцилограм перехідних процесів може практично відразу визначити, коли обладнання знаходиться в передаварійному стані або вимагає переналагодження [3]. При цьому витрати на профілактичний ремонт будуть істотно нижче, ніж в ситуації, коли несправність придбає явний характер, який буде зафіксований системою автоматики. Однак при тій кількості електроприводної техніки, яка використовується в прокатному виробництві, неможливо фізично відстежувати стан обладнання силами кваліфікованих фахівців в повному обсязі і оперативне. Інше рішення полягає в модернізації устаткування, придбання обладнання, здатного до інтелектуальної обробки інформації. Але подібне обладнання має високу вартість і перехід всього парку електроприводів на подібні системи неможливий.

\section{Аналіз останніх досліджень і публікацій}

Як об'єкт дослідження було обрано електропривод кліті листового стану безперервної прокатки. В рамках даного дослідження були поставлені наступні завдання:

1) отримання параметрів електроприводу в динаміці;

2) вибір архітектури нейронної мережі і їі навчання;

3) моделювання процесу ідентифікації та діагностики.

Якщо розглянути електричний привід як динамічний об'єкт, описуваний вектором вхідних даних, вектором внутрішнього стану і вектором вихідних даних, то, відповідно до теореми про універсальну апроксимацію $[1,2]$, штучна нейронна мережа може ідентифікувати його при наявності достатньої кількості навчальних даних. В промислових електроприводах застосовується велика кількість датчиків, тому отримання вхідних і вихідних векторів можливо.

У джерелах [2-4] наводяться способи нейромережної ідентифікації узагальнених динамічних об'єктів. $€$ досить багато публікацій з даної тематики $[2,3,6]$. Однак мало публікацій 3 нейромережної ідентифікації конкретних динамічних об'єктів, таких як електричний привід $[5,7]$, більшість же робіт мають оглядовий характер. Деяку складність застосування штучних нейронних мереж являє розробка архітектури мережі під конкретний клас об'єктів і підбір навчальних даних. До сих пір ця задача не формалізована, є лише загальні рекомендації та емпіричні дані $[2,7,8]$.

\section{Формулювання мети дослідження}

Основною метою даної роботи є розробка методу діагностики автоматизованих приводів прокатних станів, що працюють в умовах підвищених динамічних навантажень. Розроблений метод діагностування може дозволити взяти на себе функцію контролю за динамікою швидкості і оперативно попереджати відхилення в роботі електроприводу кліті.

\section{Виклад основного матеріалу}

При побудові та дослідженні електроприводу застосовувалися системи моделювання динамічних процесів Simulink i SimPowerSystems середовища розробки Matlab. Для моделювання в бібліотеці SimPowerSystems обраний електродвигун постійного струму незалежного збудження 3 наступними параметрами: $R_{я}=0,78$ Ом, $L_{я}=0,016$ Гн, $R_{b}=150$ Ом, $L_{\phi}=112,5 \Gamma_{\mathrm{H}}$, $U_{\mathrm{r}}=240 \mathrm{~B}, U_{b}=150 \mathrm{~B}, W=240$ рад/сек.

Які відповідають електродвигуну кліті листового прокатного стану. Перетворювач для спрощення моделі представлений регульованим блоком напруги, які мають затримку $\frac{1}{T_{n} s+1}$ на вході з управління. Для вирішення першого завдання було потрібно отримати необхідний набір даних роботи електроприводу в динаміці. Кількість навчальних прикладів має бути достатнім, щоб описати роботу системи у всіх реальних робочих режимах. В реальних електроприводах $\epsilon$ можливість отримання подібної інформації, або безпосередньо з датчиків, або 3 керуючих мікропроцесорних засобів. При моделюванні в Matlab використовувався сигнал випадкового процесу, згенерований за допомогою стандартного блоку Simulink. При цьому, згідно з [9], чим більше інформації, тим точніше буде відображення. В даному експерименті сигнал подавався на протязі $t=240$ с на вхідне завдання $U_{\text {вих }}$ i на вхід навантаження $M_{\text {н. }}$ Одночасно знімалися виходи по швидкості $W$ і струмом якоря $I_{\text {я }}$ І Інформація з обмотки збудження не враховувалася, припускаючи роботу тільки в першій зоні за швидкості. Дані були приведені до безрозмірного виду для зручності навчання мережі. При вирішенні другого завдання - вибір архітектури нейронної мережі - необхідно враховувати динаміку процесу, тобто мережа повинна «пам'ятати» по- 
передні стану об'єкта. Для цих цілей, як правило, застосовуються зворотні зв'язки від вихідних сигналів нейронної мережі до її входів $[7,9]$. Побудова узагальненої архітектури подібних мереж описана в джерелах $[3,8,9]$. У даній роботі була використана нейронна мережа із затримками в зворотних зв'язках, відома як модель нелінійної регресії з зовнішніми входами $N A R X \mathrm{i}$ описана в $[6,10]$. Вона виходить із звичайного багатошарового персептрону шляхом введення зворотних зв'язків із затримкою. Подібна архітектура важлива при запам'ятовуванні послідовностей сигналів. узагальнена модель має наступний вигляд:

$$
\begin{gathered}
-/ y(n+1)=\varphi(-/ y(n), \ldots,-/ y(n-q+1), \\
-/ u(n), \ldots,-/ u(n-q+1),
\end{gathered}
$$

де $\frac{\bar{y}}{y}(n)-$ вихідний вектор; $\frac{\bar{u}}{u}(n)-$ вхідний вектор; $n-$ дискретний момент часу; $q$ - порядок системи.

Застосування затримки $z^{-1}$ в зворотного зв'язку дозволяє усунути проблему стійкості мережі [5,9]. На рис. 1 приведена структура мережі $N A R X$.

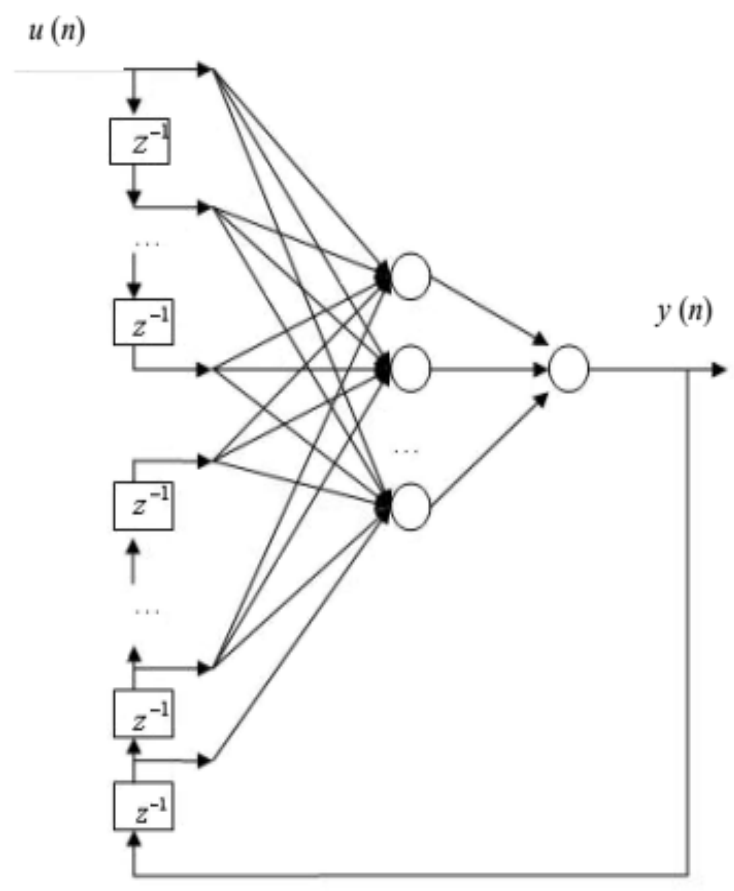

Puc. 1. Рекурентна нейронна мережа $N A R X$

В даний час немає точної методики вибору числа нейронів внутрішнього шару, евристичний ж було отримано оптимальне число нейронів в кількості 5. При більшій кількості нейронів внутрішнього шару зростає швидкість навчання, однак, падає здібних до апроксимації нейронною мережею але нових даних $[6,9]$. При малому числі нейронів мережу може не навчитися з достатньою точністю. У внутрішньому шарі мережі застосована гіперболічна тангенціальна функція активації, що має формулу:

$$
\operatorname{tansing}(n)=\frac{2}{1+e^{2 N}}-1,
$$

де $N=\sum_{j=0}^{J} U_{i} \cdot W_{i j}$ - сума множин вхідного вектору і вагових коефіцієнтів першого шару.

У вихідному шарі задана лінійна функція активації, лінійно відображає сигнал на вихід:

$$
\operatorname{purelin}(N)=N \text {, }
$$

де $N$ - сума множин виходів нейронів внутрішнього шару на вагові коефіцієнти вихідного шару. 
Для навчання мережі використовувався алгоритм Левенберга-Марквардта, який реалізує навчання за допомогою підстроювання вагових коефіцієнтів нейронної мережі в залежності від похибки виходу мережі і навчальної множини [6]. Навчання проводилося протягом 300 ітерацій, при цьому помилка навчання склала $E_{\mathrm{rrL}}=7 \cdot 10^{-5}$. Рішення третьої задачі було розділене на декілька етапів. Спочатку було вироблено порівняльне моделювання при незмінних параметрах електроприводу, що імітувало нормальний режим роботи. Після цього імітувались зміни робочих параметрів, які свідчили про порушеннях в роботі електропривода, і моделювання повторювалося. Так, найбільш поширене порушення цілісності ізоляції якірного ланцюга: перегрів двигуна або поганий контакт в колекторі викликають зміна опору і індуктивності якірного ланцюга, при цьому змінюється динаміка роботи всієї кліті. Якщо своєчасно не відстежити цей процес, то він призводить до перегріву двигуна і його виходу з ладу. Крім того моделювання показало, що зміна опору якірного ланцюга знижує ефективність системи управління, викликаючи коливальний процес. Це пов'язано з тим, що класичні системи підлеглого регулювання не здатні компенсувати зміну великих постійних часу в широких межах і настройка коефіцієнтів регуляторів стає неефективною [10]. Розроблений метод діагностики дозволяє виявити цей дефект на ранній стадії.

Інший поширений вид порушень пов'язаний з руйнуванням підшипникових вузлів або редуктора. Це призводить до зміни моменту інерції, коливального процесу, посилення вібрацій, що також веде до руйнування механічної частини. Моделювання показало, що дана проблема також може бути діагностована запропонованим методом на ранніх стадіях, що не приводять до сильних руйнувань. Для моделювання в Simulink була зібрана схема, що складається з електроприводу постійного струму, еквівалентного тому, що використовуються в листових безперервних прокатних станах і його навченої нейромережевої моделі [3]. Для стабілізації швидкості $W$ в схему був включений пропорційно-інтегральний регулятор, налаштований для електроприводу кліті і скопійований для нейромережевої моделі.

Моделювання проводилося протягом $t=30$ с. Імітувалась робота кліті прокатного стану по наступному алгоритму, який відповідав реальним умовам експлуатації:

- валки розганялися до швидкості захоплення металу на 5 с;

- відбувалося захоплення металу на 8 c;

- кліть розганяла до робочої швидкості на 12 c;

- метал залишав кліть на 22 c;

- зупинка кліті відбувалася на 25 с.

При перевірці нейромережевої моделі параметри електроприводу були в нормі і відповідали тим, що були при навчанні нейромережевої моделі. На рис. 2 зображений результат моделювання, де при однакових вхідних впливах відображена динаміка електроприводу і його нейромережної моделі. Похибка відхилення динаміки нейромережної моделі від динаміки електроприводу розрахована за формулою:

$$
E_{\text {rr }}=\frac{1}{N} \sum_{i}^{N} \cdot\left(W_{\text {neyr }}-W_{\text {drive }}\right)^{2}
$$

де $E_{\text {rт }}$ - середньоквадратичне відхилення, $W_{\text {nеуг }}$ - вектор зміни швидкості нейромережевої моделі, $W_{\text {drive }}$ - вектор зміни швидкості електроприводу, $N$ - розмірність вектору.

Для нормального режиму роботи середньоквадратична похибка склала $E_{\mathrm{rr}}=2,4 \cdot 10^{-5}$, що говорить про високу точність нейромережної моделі і з графіків видно, що вони практично збігаються На наступному етапі були внесені зміни, характерні для передаварійних ситуацій в електроприводі прокатного стану. Імітувалося зміна опору якірного ланцюга двигуна внаслідок порушень в ізоляції. Результати моделювання при зміненому опорі кола якорю наведені на рис. 3. Система регулювання вже не могла повністю компенсувати постійну якірного ланцюга i помітний коливальний процес. На рис. 3 чітко видно відхилення динаміки електроприводу від його нейромережної моделі під час перехідних процесів. При досягненні уставок задає впливу і при зміні моменту опору спостерігалося перерегулювання швидкості і коливальний процес 3 загасанням. Ефективне значення похибка різко збільшилася і склала $E_{\mathrm{rr}}=3,8$. 


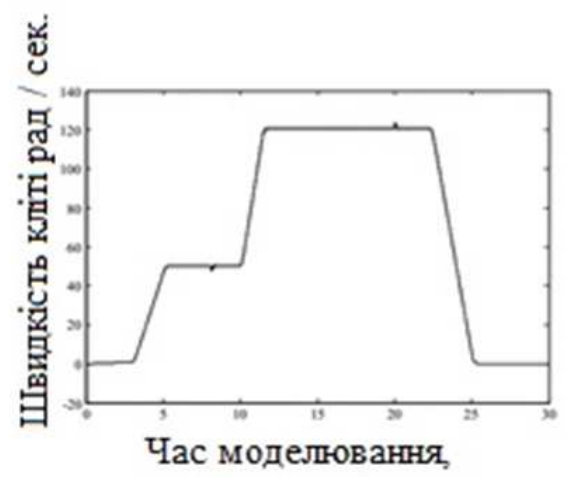

Рuc. 2. Графік порівняльного моделювання швидкостей моделі реального електроприводу i нейромережевої моделі при незмінних параметрах електроприводу, що імітують нормальний режим роботи

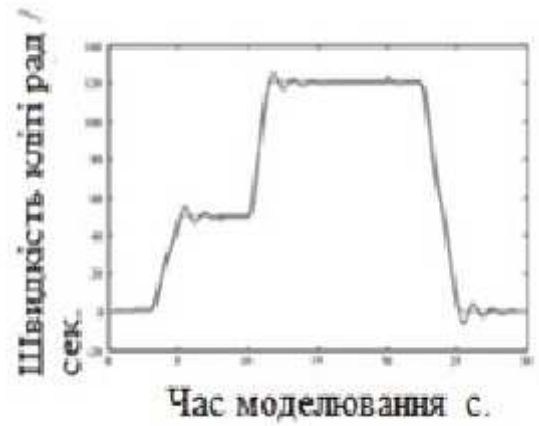

Рuc. 3. Графік порівняльного моделювання швидкостей моделі реального електроприводу і ї моделі при зміні моменту інерції на валу двигуна, що імітує порушення в механічної частини

Подібний коливальний процес в реальних умовах не буде зафіксований системою автоматики, так як параметри або їх похідні будуть в межах допусків. Але несвоєчасне виявили ня веде до швидкого зносу і руйнування робочих вузлів устаткування через коливальних процесів. Крім того, погіршується якість системи управління. Якщо оперативне виявляти подібне від відхилень, то можна отримати економію по двом статтям:

- ремонт зажадає менше фінансових витрат в зв'язку з тим, що несправність буде локалізована до того, як потягне за собою великі поломки;

- ремонт займе менше часу, якщо несправність локалізована на ранній стадії.

\section{Висновки}

Розроблений метод діагностування дозволяє взяти на себе функцію контролю за динамікою швидкості і оперативно попереджати відхилення в роботі електроприводу прокатного стану кліті. Проведено позитивні випробування в лабораторних умовах на розроблених математичних моделях. Математичні моделі показали свою адекватність при імітації різних порушень, таких як:

- руйнування підшипникових вузлів електродвигуна;

- заклинювання редуктора і системи валків кліті;

- порушення цілісності обмоток якорz;

- знос щіткового апарату в колекторі;

- перегрів електродвигуна;

- погіршення якості системи управління.

Застосування розглянутого в даній роботі методу цілком може бути розширено і застосовано до інших типів електроприводів металургійного виробництва, а так само до інших технічних пристроїв і агрегатів для оцінки їх стану.

\section{Список використаної літератури}

1. Горбань А.Н. Обобщенная аппроксимационная теорема и вычислительные возможности нейронных сетей, Сибирский журнал вычислительной математики, РАН. Сибирское отделение. Новосибирск, 1998. Т. 1. № 1. С. 11-24.

2. Макаров И.М., В.М. Лохин Интеллектуальные системы автоматического управления. М.: ФИЗМАТЛИТ, 2001. 576 с.

3. Кожевников А.В. Диагностирование приводов прокатных станов с помощью нейросетевой оценки, Металлургические процессы и оборудование. № 3(33). 2013. С. 54-60.

4. Терехов В.А., Ефимов Д.В., Тюкин И.Ю. Нейросетевые системы управления. М.: Высш. школа, 2002. 183 с. 
5. Волков В.Н., А.В. Кожевников Нейросетевая идентификация электропривода постоянного тока. Конф. «Современные научные исследования и инновации», 2013. Апрель. - URL: [http://web.snauka.ru/issues/2013/04/23648]2013/04/23648.

6. Клепников В.Б. Применение методов нейронных сетей и генетических алгоритмов в решении задач управления електроприводами. Электротехника.1999. № 5.С. 2-6.

7. Медведев В.С. Нейронные сети. MATLAB6. Под общ. ред. В.Г.Потемкина. - М.: ДИАЛОГМИФИ, 2002. $496 \mathrm{c}$.

8. Обзор методов нейроуправления http: [ailen.org] / А.Н. Чернодуб, Д.А. Дзюба.

9. Оссовский С. Нейронные сети для обработки информации. Пер. с польского И.Д. Рудинского. - М. Финансы и статистика, 2002. 344 с

10.Хайкин С. Нейронные сети: полный курс. [пер с англ] - изд. дом «Вільямс». М., 2006. 1104 с.

11.Терехов В.М., Осипов О.И. Системы управления электроприводов. М.: Академия, 2005. 300 с.

\title{
DIAGNOSTICS OF AUTOMATED ROLLING MILL SYSTEMS WITH THE USE OF THE NEURAL NETWORK \\ Meshchaninov S.K. Sai O.V., Bagri V.V., Voloshin R.V.
}

\begin{abstract}
The paper presents a method of estimating the state of electric drives based on the construction of a neural network. The example of a DC electric drive describes an experiment that demonstrates the effectiveness of this approach. This method can be used to diagnose the condition of electric drives of rolling mills of metallurgical production. Such systems are becoming increasingly popular as drive vehicles for high-performance lines. In the metallurgical industry, automated electric drive is used in the vast majority of plants and technological complexes. Up to half of all electricity consumed by metallurgical enterprises is electric drive equipment.

Special requirements in metallurgy are imposed on automated drives of sheet continuous rolling mills: there are traditionally used DC drives with independent excitation, which have good performance under dynamic loads and are able to provide smooth speed control over wide ranges. Like any other technical device, rolling mill drives require maintenance. In this case, the quality of operation of electric drives and the effective planning of repair and adjustment works indirectly affect such production indicators as: rolling mill performance, rolling quality and production cost.

Optimal adjustment of the control system allows us to reduce power consumption by the mill and eliminate shortages, and timely detection of faults at the initial stage avoids expensive repair and downtime of the entire rolling mill. Existing systems of automatic control of electric drives of continuous sheet rolling mills are capable of on-the-fly detecting and localizing emergencies. These situations include problems with conversion equipment, electric motors, or mechanical parts. However, fault detection by the automation system often occurs at a stage where the destruction is significant and requires major repairs.

The main purpose of this work is to develop a method of diagnostics of automated rolling mill drivers operating under conditions of high dynamic loads. The developed method of diagnosis can allow us to assume the function of the dynamics control of the speed and promptly prevent deviations in the operation of the electric drive rolling mill.
\end{abstract}

\section{References}

[1] Gorban A.N. (1998). Obshay approcsimacionnay teorema i vicheslitelnie vozmozhnosti neironnih setey [Generalized approximation theorem and computational capabilities of neural networks]. Siberian Journal of Computational Mathematics / RAS. Siberian branch. № 1, 11-24. [Novosibirsk]. 
[2] Makarov I.M., Lohin M. M. (2001) Intelektualnse sistemi avtomaticheskogo upravleniy [Intelligent automatic control systems]. FIZMATLIT, 567 [Moscow].

[3] Kozhevnikov A.V. (2013) Diagnostirovanie privodov prokatnih stanov s pomoshu neirositevoy ocenks [Diagnostics of rolling mill drives using neural network assessment]. № 3(33), 54-60 [Moscow].

[4] Terehov V.A., Efimov D.V., Tukin I.U. (2002) Neirositevie sistemi upravleniy [Neural network control systems]. Higher school, 183 [Moscow].

[5] Volkov V.N., Kozhevnikov A.V.(2013) Neirositevay indefikaciy elektroprivoda postoynogo toka [Neural network identification of a DC electric drive]. Modern research and innovation. 2013. April, URL: http://web.snauka.ru/issues/2013/04/23648 2013/04/23648.

[6] Klepnikov V.B. (1999) Primenenie metodov neironyh setei i geneticheskih algoritmov v reshenii zadach upravleniy elektroprivodami [Application of neural network methods and genetic algorithms in solving problems of electric drive control]. Electrical Engineering № 5, 2-6 [Moscow].

[7] Medvedev V.S. (2002) Neironnie seti MATLAB6 [Neural networks. MATLAB6]. DIALOGUEMEPhI, 496 [Moscow].

[8] Chernodub A.N.,Dzuba D.A. (2002) Obzor metjdov neiroupravleniy [Overview of neurocontrol methods]. URL: http://ailen.org/

[9] Ossovskii S.(2002) Neironnie seti dly obrabotki informacii [Overview of neurocontrol methods]. Finance and Statistics, 334 [Moscow].

[10] Haikin S. (2006) Neironnie seti polniy kurs [Neural networks: full course]. Hom. Viliyms, 1104 [Moscow].

[11] Terehov V.M., Osipov O.I. (2005) Sistemi upravleniy elektroprivodom [Electric drive control systems]. Academy, 300 [Moscow]. 